This item was submitted to Loughborough's Research Repository by the author.

Items in Figshare are protected by copyright, with all rights reserved, unless otherwise indicated.

\title{
The ballistic impact performance of nanocrystalline zirconia-toughened alumina (nZTA) and alumina ceramics
}

PLEASE CITE THE PUBLISHED VERSION

https://doi.org/10.1016/j.jeurceramsoc.2020.09.068

\section{PUBLISHER}

Elsevier BV

VERSION

AM (Accepted Manuscript)

\section{PUBLISHER STATEMENT}

This paper was accepted for publication in the journal Journal of the European Ceramic Society and the definitive published version is available at https://doi.org/10.1016/j.jeurceramsoc.2020.09.068

\section{LICENCE}

CC BY-NC-ND 4.0

\section{REPOSITORY RECORD}

Wade-Zhu, Y, J Wade-Zhu, Houzheng Wu, J Binner, and Vaidhy Vaidhyanathan. 2020. "The Ballistic Impact Performance of Nanocrystalline Zirconia-toughened Alumina (nzta) and Alumina Ceramics". Loughborough University. https://hdl.handle.net/2134/13083998.v1. 


\title{
The Ballistic Impact Performance of Nanocrystalline Zirconia- Toughened Alumina (nZTA) and Alumina Ceramics
}

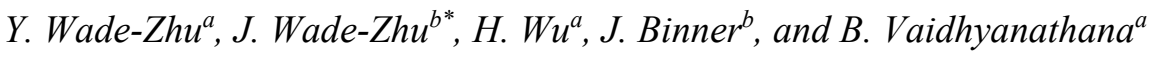 \\ ${ }^{a}$ Department of Materials, Loughborough University, Loughborough, LE11 3TU, UK \\ ${ }^{b}$ School of Metallurgy \& Materials, University of Birmingham, B15 2TT, UK
}

\begin{abstract}
The ballistic impact performance of nanocrystalline zirconia-toughened alumina (nZTA) ceramics, comprising $15 \mathrm{wt} \%$ nano-yttria-stabilised zirconia in a sub-micron alumina matrix, have been studied through depth of penetration tests and compared to the results for monolithic alumina. The penetration resistance of each material was evaluated by fitting the penetration depth results against the thickness of the ceramic targets. These results show that, despite micro-Raman analysis of the nZTA confirming the occurrence of the classic tetragonal-to-monoclinic zirconia phase transformation, nZTA ceramics provide no benefit with respects to penetration resistance compared to monolithic alumina. Analysis of the fragments generated using $\mathrm{Cr}^{3+} / \mathrm{Al}_{2} \mathrm{O}_{3}$ fluorescence spectroscopy shows that both the nZTA and alumina experience similar amounts of plastic deformation as a function of fragment size, with finer fragments $(<150 \mu \mathrm{m})$ exhibiting more plastic deformation than coarser fragments $(>150 \mu \mathrm{m})$. These results are validated through fracture surface observations and subsurface dislocation analysis using SEM and TEM respectively.
\end{abstract}

Keywords: ballistic performance, zirconia toughened alumina, fragment analysis, phase transformation, plastic deformation.

\section{Introduction}

Alumina ceramics are widely used for armour applications due to their low density, excellent cost-toperformance ratio, and ease of fabrication [1]. Their role in hybrid armour systems is to act as the hard strike face for incoming contacts, blunting impacting projectiles during the dwell phase $(<10 \mu \mathrm{s})$ and being comminuted (pulverised) into fragments that erode them during the penetration phase ( $>10 \mu \mathrm{s})$ in order to dissipate their kinetic energy over a larger contact area [2,3]. Consequently, alumina-based armour ceramics with microstructures and mechanical / physical properties tailored to promote plastic

*Corresponding author:

E-mail address: j.m.wade@bham.ac.uk (J. Wade-Zhu) 
deformation and fragmentation at the projectile tip and which generate fragments of higher abrasion efficiency within their comminution zones tend to offer superior ballistic performance.

In a comprehensive review of ballistic data by Krell and Strassburger [4] it was concluded that the dominant mechanical / physical properties determining the ballistic performance of oxide ceramics, specially polycrystalline and single-crystal $\mathrm{Al}_{2} \mathrm{O}_{3}$ and $\mathrm{MgAl}_{2} \mathrm{O}_{4}$, follows a hierarchical order of influences, the most important being the mode of ceramic fragmentation, followed by the Young's Modulus of the entire hybrid armour system (including the front plate + backing material) and then the hardness of the ceramic. A high Young's modulus provides resistance to bending deformation on projectile-target contact, extending the $d w e l l$ phase and delaying the onset of fragmentation to allow for further blunting to occur. Meanwhile, a high hardness generates fragments of greater abrasion efficiency, translating into higher projectile erosion rates during the penetration phase. However, the hierarchical order of influences means that realising the aforementioned benefits associated with oxide ceramics of high Young's modulus and hardness is entirely contingent on the existence of an ideal mode of fragmentation. If the mode of fragmentation is suboptimal, then a high Young's modulus and high hardness will not provide any added benefit to armour performance [4].

The mode of fragmentation is a complex term that encompasses the size, mass and shape of the fragments produced during ballistic impacts. Coarser fragments of high roughness and with sharp surface features offer the best performance in terms of ballistic resistance [5], promoting the ploughing and cutting mechanisms associated with high erosion rates at the projectile tip [6,7]. In accordance with the model of Grady [8], the size of the fragments, $d$, generated during projectile-target contacts is governed by the following equation:

$$
d=\left[\frac{\sqrt{20} K_{I C}}{\rho C \dot{\varepsilon}}\right]^{2 / 3}
$$

where $K_{I c}$ is the fracture toughness, $\rho$ is density, $C$ the sonic velocity of target material, and $\dot{\varepsilon}$ is the tensile hoop strain rate and is approximately $\dot{\varepsilon}=4 \times 10^{4} / \mathrm{s}$. Based on eq. (1), ceramics that have higher $K_{I c}$ values will generate coarser fragment sizes. Therefore, it may be possible to improve the ballistic performance of alumina-based armour ceramics by engineering their microstructures to increase their fracture toughness. A well-established approach to achieving this in alumina is through the addition of zirconia to form zirconia-toughened alumina (ZTA). ZTA enhances the quasi-static fracture toughness of alumina via transformation toughening ( $K_{I c}$ values of up to $12 \mathrm{MPa} \mathrm{m}^{0.5}$ [9]). Transformation toughening in ZTA involves the stress-induced tetragonal-to-monoclinic $(t-m)$ phase transformation of the metastable zirconia grains in the stress field of an advancing crack tip [10,11]. During this process, 
the simultaneous volume expansion $(\sim 4 \%)$ and shear strain $(\sim 6 \%)$ that coincides with such a transformation inhibits crack propagation by applying a neutralising compressive stress near the crack tip, effectively shielding it from the applied tensile stress $[9,12]$.

ZTA ceramics are particularly advantageous in the microstructural design of armour ceramics, facilitating significant improvements in fracture toughness without undesirable trade-offs in other key properties such as hardness and Young's modulus. Further enhancements in armour performance may be sort through the preparation of nanocrystalline ZTA ceramics (nZTA), which utilise grain refinement to maximise hardness while also offering the same toughening as conventional ZTA. However, despite their potential as armour materials, only a limited number of papers have focused on the high-strain rate performance of ZTA and nZTA ceramics [13], with conflicting results [14,15]. In long rod projectile (LRP) tests performed by Zhang and Li, residual penetration depths at peak impact velocities of 1498$1520 \mathrm{~ms}^{-1}$ were found to be $24 \%$ lower in $10 \mathrm{wt} \%$ ZTA ceramics compared with $95 \%$ alumina [14]. Similar LRP tests in earlier work by Bless and Hanchak performed at impact velocities of $\sim 1370-1390$ $\mathrm{ms}^{-1}$ found more scattered results, yielding residual penetration depths in ZTA of $0.5 \mathrm{~mm}$ and $52.4 \mathrm{~mm}$ compared to $30 \mathrm{~mm}$ in hot-pressed alumina [16]. Ballistic tests by Savio et al, completed using 7.62 $\mathrm{mm}$ armour piecing rounds and a 6063-T6 aluminium alloy backing material to capture the penetrating projectiles, reported no appreciable difference in the ballistic performance between $99.5 \%$ alumina and $10 \%$ ZTA ceramics [15]. This paper seeks to provide further clarity on the potential of phase transformation toughening in ZTA and nZTA ceramics as a means of improving the ballistic performance of pure alumina.

Thus, nZTA and alumina ceramics were prepared and subjected to ballistic-scale testing. Quasi-static measurements demonstrated the nZTA ceramics to have a $30 \%$ higher $K_{I c}$, all other properties being similar in both materials. Depth of penetration (DOP) measurements were used to comparatively assess the ballistic performance of the ceramics produced whilst post-impact analysis of the size of fragments generated during ballistic testing enabled an understanding of the comminution process in both ceramics. Micro-Raman and $\mathrm{Cr}^{3+}$ fluorescence spectroscopy on the same fragments was used to quantify the amount of zirconia phase transformation and plastic deformation that occurred, respectively. SEM and TEM images provided support for the findings of the spectroscopic techniques. A discussion is also presented on the role the zirconia phase transformation had on the ballistic impact-induced damage (i.e. fragmentation and plastic deformation) in the nZTA and the influence this had on the ceramics' overall ballistic performance compared with the pure alumina control.

\section{Experimental Procedure}




\subsection{Materials Preparation}

nZTA ceramics containing $15 \mathrm{wt} \%$ yttria stabilised zirconia (YSZ) were prepared using raw constituents of a well-dispersed submicron alumina suspension (Baikowski, Annecy, France) and an aqueous YSZ nanosuspension (MEL Chemical, Manchester, UK). Control samples of monolithic alumina of comparable grain size were prepared using solely the submicron alumina suspension. The attributes of the two as-received suspensions are summarised in Table 1. Fabrication involved mixing them in the correct proportions and then concentrating the resulting suspension to increase the solid content level to $\sim 57 \mathrm{wt} \%$ by continuously stirring it at $60^{\circ} \mathrm{C}$. In order to break up any agglomerates forming during concentration, every 30 minutes the suspension was subjected to sonication for 1 minute using an ultrasonicator (MSE Scientific Instruments, Manchester, UK). The final viscosity of the suspension after concentration was $\sim 80 \mathrm{mPa}$ at $100 \mathrm{~s}^{-1}$ shear rate. The same procedure was also performed on the as-received alumina suspension that was used to form the control alumina ceramics.

Table 1: Properties of the of the as-received alumina and YSZ suspensions

\begin{tabular}{ccccc}
\hline Suspension & $\begin{array}{c}\text { Yttria content } \\
/ \mathrm{mol} \%\end{array}$ & $\begin{array}{c}\text { Solid content } \\
/ \mathrm{wt} \%\end{array}$ & $\mathrm{pH}$ & $\begin{array}{c}\mathrm{D}_{50} \text { particle size } \\
/ \mathrm{nm}\end{array}$ \\
\hline YSZ & 1.5 & 26.5 & 2.50 & 13 \\
Alumina & - & 50 & 3.52 & 200 \\
\hline
\end{tabular}

The concentrated suspensions were subsequently spray-freeze dried at $-62^{\circ} \mathrm{C}$ under a vacuum of $<100$ mTorr. The resultant granules were then sieved to control their size to a range of between $125-250$ $\mu \mathrm{m}$. To manufacture the large disc samples required for ballistic testing, green bodies were first prepared through uniaxial die pressing at a maximum pressure of $50 \mathrm{MPa}$ using an $80 \mathrm{~mm}$ diameter steel die. This was then followed by cold isostatic pressing (CIP) at $200 \mathrm{MPa}$. All as-pressed green bodies had a density of $\sim 55 \%$ of the material's theoretical density. Sintering of the green bodies was completed in air at $1400^{\circ} \mathrm{C}$ for the alumina and $1500^{\circ} \mathrm{C}$ for the nZTA using a heating rate of $10^{\circ} \mathrm{C} \mathrm{min}-$ ${ }^{1}$ and a dwell at peak temperature of $10 \mathrm{~h}$. After sintering, all samples had a diameter of $\sim 60 \mathrm{~mm}$ and thickness of between $6-7 \mathrm{~mm}$. This is consistent with the dimensions recommended for DOP testing.

\subsection{Materials Characterisation}

The density of the nZTA and alumina ceramics was measured using the Archimedes method with water as the immersive medium. Grain size analysis was completed by thermally-etching polished specimens at $150^{\circ} \mathrm{C}$ below their respective peak sintering temperatures in air for $15 \mathrm{~min}$. Images of these grain structures were then captured using a Leo 1530 VP FEGSEM (Zeiss, Germany) at an accelerating 
voltage of $5 \mathrm{kV}$. The mean grain size was determined following the linear intercept method described in ASTM E112-96 and using at least three micrographs or a total of 300 grains.

An HM-124 hardness tester (Mitutoyo, Japan) was used to measure and compare the Vickers hardness $(H V)$ and indentation fracture toughness properties of the nZTA and alumina ceramics. Hardness measurements were performed under a load of $1 \mathrm{~kg}$ and in accordance with the approach given in ASTM E384. Indentation fracture toughness measurements were completed under a load of $10 \mathrm{~kg}$ and calculated using the equation of Anstis et al [17].

$\mathrm{X}$-ray diffraction (XRD) analysis was performed on all nZTA ceramics using a benchtop D2 phaser system (Bruker, USA) to ensure that no phase transformation had taken place prior to ballistic testing.

\subsection{Ballistic Testing - Depth of Penetration}

The ballistic performance of the nZTA and alumina ceramics was assessed by conducting DOP tests. As shown in the schematic illustration in Fig. 1(a), the DOP test set-up consisted of a gun that was mounted perpendicular to the front face of the ceramic target at a distance of $10 \mathrm{~m}$, a set of light screens used to measure projectile velocities, the ceramic target to be tested and a polycarbonate rod backing to capture the projectile after penetration of the ceramic target. Shear-wave couplant gel was placed as an interlayer between the ceramic target and the polycarbonate backing to inhibit the generation of reflective shockwaves that could introduce further variance to the DOP results. A photograph of the clamping system used to hold the ceramic target in place is shown in Fig. 1(b). This consisted of two rectangular steel blocks with a semi-circle cut out on one side that were bolted together to make a hole in middle in which the ceramic target was positioned and secured by two aluminium C-clips, one on the front face and one on the rear face. At the front face of the ceramic target, a U-shaped ballistic gel cup (Defensible Ballistics Ltd, UK) was attached to capture all ceramic fragments/debris generated during testing. In the majority of cases, this was $\sim 70 \%$ of the mass of the original target. 
(a)

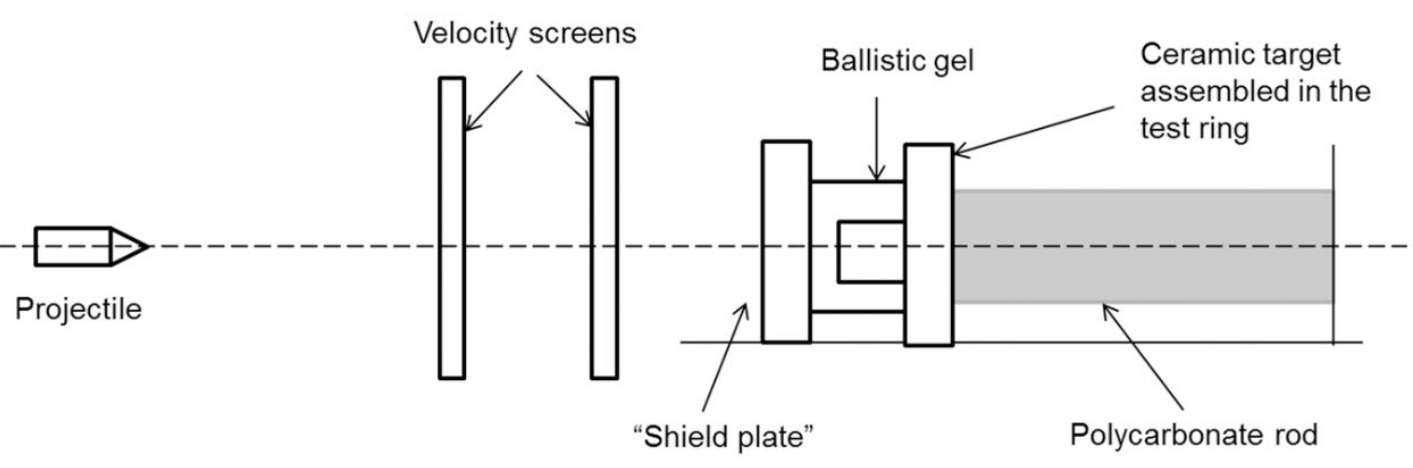

(b)

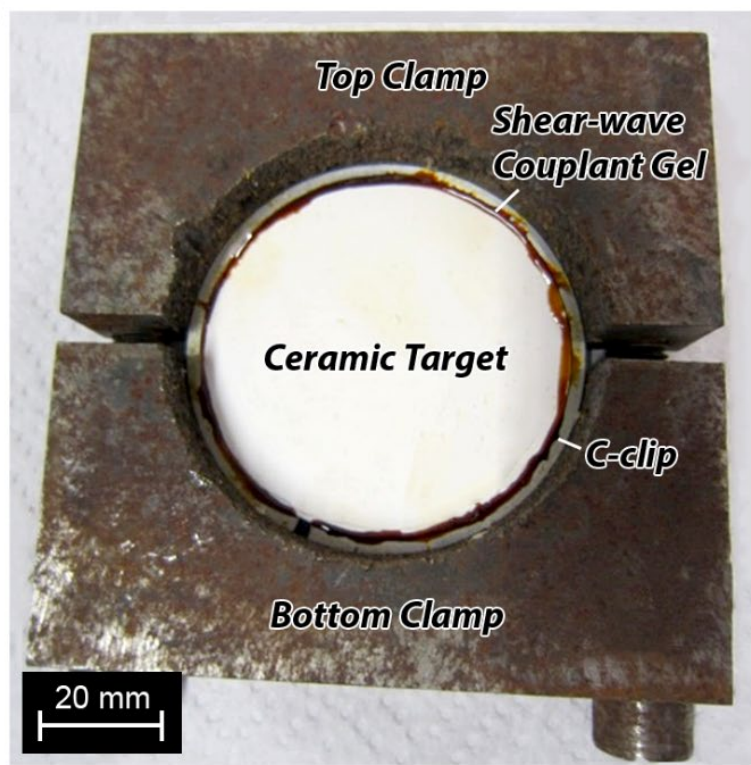

(c)
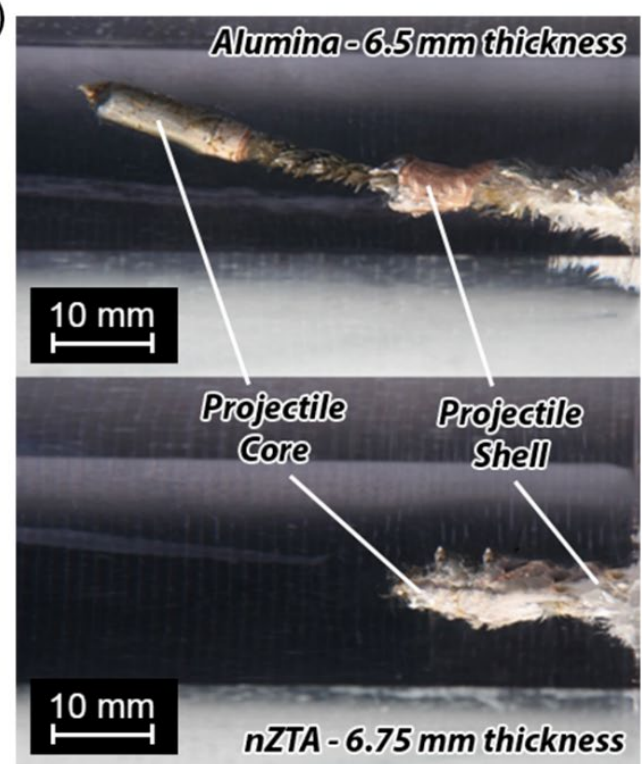

Fig. 1: Ballistic testing of the as-prepared nZTA and alumina ceramics: (a) schematic of the test configuration, (b) ceramic target mounting system, and (c) projectiles captured in the polycarbonate rod backing used to measure DOP.

All DOP tests performed were single shot tests using a $7.62 \times 54 \mathrm{~mm}$ armour piercing M2 round fired at a velocity of $875 \pm 25 \mathrm{~ms}^{-1}$. In order to ensure that the DOP test results obtained were not influenced by differences in the surface finish achievable in the nZTA and alumina ceramics, all ceramic discs were tested in an as-sintered, unpolished state.

After ballistic testing, the DOP achieved by each projectile was determined by measuring the distance travelled through the polycarbonate rod, see Fig. 1(c). The fragments / debris that had collected in the ballistic gel cup during testing were also removed and separated into specific size ranges for further analysis. This process involved feeding the fragments through various sieves with meshes designed to separate them into size ranges of $>2000 \mu \mathrm{m}, 1000-2000 \mu \mathrm{m}, 500-1000 \mu \mathrm{m}, 250-500 \mu \mathrm{m}, 150-$ $250 \mu \mathrm{m}, 100-150 \mu \mathrm{m}$ and $<100 \mu \mathrm{m}$. As detailed below, representative samples of the fragments from 
each size range were further characterised using a variety of spectroscopic and electron microscopy techniques.

\subsection{Characterisation of Fragments Recovered from Ballistic Tests}

\subsubsection{Raman Spectroscopy Analysis}

Raman spectroscopy was used to quantify the amount of $t-m$ phase transformation in the zirconia of randomly-selected nZTA fragments after ballistic testing. Analysis was performed using a Horiba Yvon Raman LabramHR micro Raman spectrometer (Horiba Jobin Yvon SAS, France) equipped with a 633 $\mathrm{nm}$ He-Ne laser and a liquid nitrogen cooled CCD detector. For all tests, the laser was powered at 17 $\mathrm{mW}$ and the spectrum integration time was set at $40 \mathrm{~s}$. An objective lens of $50 \times$ was used to give an approximate laser spot size on the tested sample of $\sim 2 \mu \mathrm{m}$. Instrumental calibration was completed using a silicon standard. Scans were performed over a spectrum range of $100-400 \mathrm{~cm}^{-1}$ so that doublet peaks of monoclinic (at $181 \mathrm{~cm}^{-1}$ and $192 \mathrm{~cm}^{-1}$ ) and tetragonal (at $148 \mathrm{~cm}^{-1}$ and $264 \mathrm{~cm}^{-1}$ ) zirconia were included [18]. The fraction of monoclinic zirconia that had transformed from tetragonal was estimated using the following equation [18]:

$$
m=\frac{I_{m}^{181}+I_{m}^{192}}{0.97\left(I_{t}^{148}+I_{t}^{264}\right)+I_{m}^{181}+I_{m}^{192}}
$$

where $I$ equates to the maximum intensity / height of the peak at the wavenumber listed in the superscript, with subscripts of $m$ and $t$ indicating whether the wavenumber was that of the monoclinic or tetragonal crystal phase respectively. Scans involved probing at least 10 random sites across the surfaces of each fragment, the final fraction of monoclinic zirconia reported being an average of all the measurements.

\subsection{2 $\mathrm{Cr}^{3+}$ Fluorescence Spectroscopy Analysis}

The aforementioned Raman microscope was also used to perform $\mathrm{Cr}^{3+} / \mathrm{Al}_{2} \mathrm{O}_{3}$ fluorescence microscopy on the same nZTA fragments described above, as well as fragments generated from the alumina ceramic targets after ballistic testing and was employed to quantify residual stresses and dislocation densities present in the alumina phase. More details on this piezospectroscopic technique are given elsewhere [19].

All spectra were collected over a range of 14,250 to $14,550 \mathrm{~cm}^{-1}$ to ensure the acquisition of the classic $\mathrm{R} 1\left(\sim 14,402 \mathrm{~cm}^{-1}\right)$ and R2 $\left(\sim 14,430 \mathrm{~cm}^{-1}\right)$ chromophoric doublets of alumina. Each measurement made 
was an average of two scans with integration times of $2 \mathrm{~s}$. Measurements were made at a minimum of 10 different locations across each selected fragment and averaged to give a final result.

Peak fitting software, PeakFit (Systat Software Inc., USA), was used to fit the R1 peak of each measurement to a Voight profile, a convolution of the Gaussian and Lorentzian functions. R1 peak shifting and broadening was quantified by taking the mean peak centre position and FWHM of the R1 peaks from scans made across the fragments and subtracting them from those acquired across a stressfree fracture surface of alumina. The calculated difference was then used to estimate the residual stresses and dislocation densities present in the alumina fragments and the alumina phase of the nZTA fragments based on the models of Grabner [19] and $\mathrm{Wu}[20]$.

\subsubsection{SEM and TEM analysis of nZTA fragments}

Analysis of the topography of the recovered nZTA and alumina fragments was performed under a Carl Zeiss (Leo) 1530 VP FEG-SEM (Carl Zeiss, Cambridge, UK) under an accelerating voltage of $5.00 \mathrm{kV}$. Subsurface observations of dislocations in the same nZTA and alumina fragments were completed under TEM (JEOL 2000FX, JEOL, Japan) using an accelerating voltage of $200 \mathrm{kV}$. The thin foil liftouts used for TEM analysis were prepared using a Nova Nanolab 600 Dualbeam FIB system (FEI, Netherlands). Using a Ga+ beam under $30 \mathrm{kV}$ voltage and $20 \mathrm{nA}$ current, specimens measuring $10-11$ $\mu \mathrm{m}$ wide, $\sim 8 \mu \mathrm{m}$ deep and $150-200 \mathrm{~nm}$ thick were produced. These were further thinned using a reduced ion beam current of $0.1-1 \mathrm{nA}$ until a final thickness of $\sim 10-20 \mathrm{~nm}$ was achieved.

\section{Results}

\subsection{Material Microstructures and Properties}

The microstructures of the nZTA and alumina ceramics prepared for the ballistic experiments are presented in Fig. 2(a-b). As shown, the alumina grain structure of both ceramics is largely comparable, the average grain size being measured at $\sim 1 \mu \mathrm{m}$, see Table 2 . In the nZTA ceramic, the zirconia phase, the grains of lighter contrast in Fig. 2(a), are exclusively located at intergranular sites along grain boundaries and predominately at triple grain junctions. This confirms that the microstructure of the nZTA ceramic was that of an inter-type ceramic nanocomposite [21], a structure that is typical of ZTA / nZTA ceramics [22]. 


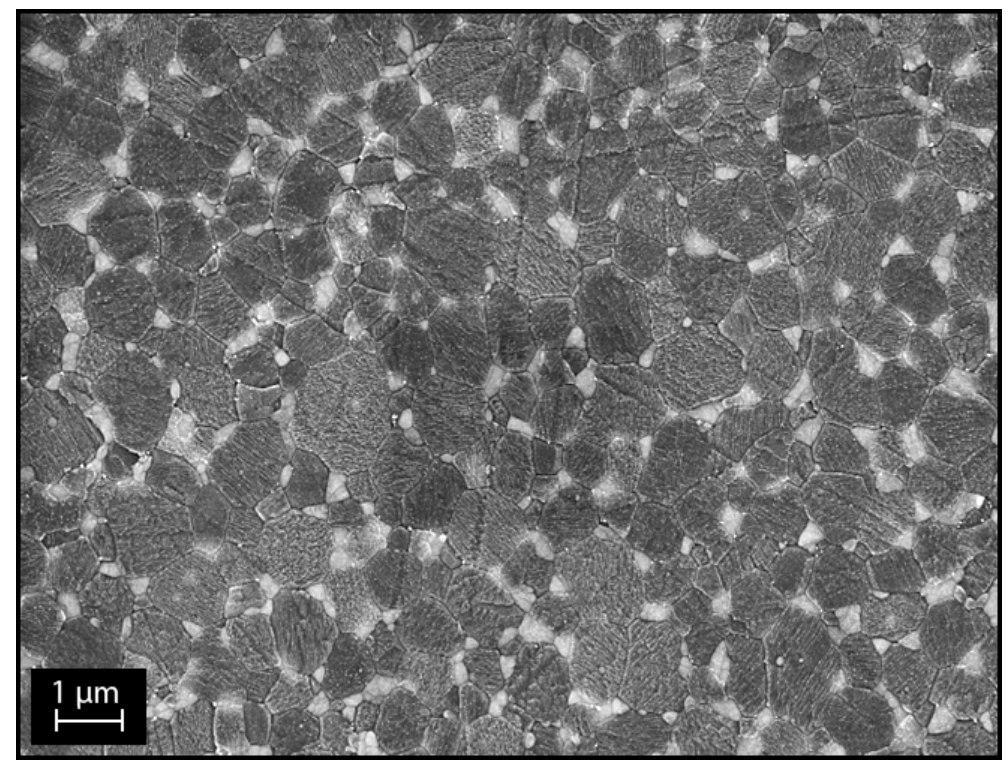

(a)

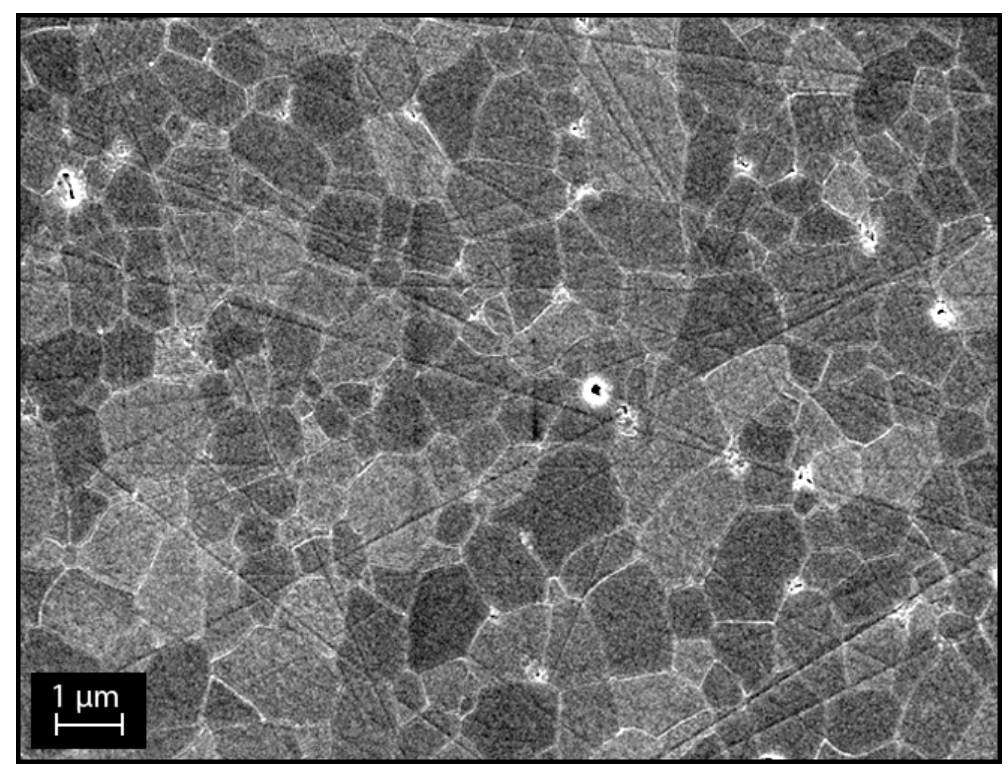

(b)

Fig. 2: Representative grain structures of as-prepared ceramics: (a) nZTA, and (b) alumina. Note, the smaller white grains in (a) is the zirconia phase and the darker grains are the alumina.

Measurements of density, hardness and fracture toughness are presented in Table 2 and confirm that both materials were very similar in terms of their properties, the only differentiator being the $30 \%$ higher $K_{I c}$ of the nZTA compared to the monolithic alumina. Given the comparable microstructural characteristics and similar hardness values, the nZTA alumina ceramics fabricated as part of this study present an excellent comparison from which the effect of transformation toughening on the ballistic performance of zirconia-toughened ceramic composites could be assessed. 
Table 2: Summary of the density, mean grain size, hardness and fracture toughness of alumina and nZTA.

\begin{tabular}{|c|c|c|c|c|c|c|}
\hline \multirow[b]{2}{*}{ Sample } & \multirow{2}{*}{$\begin{array}{c}\text { Density / } \mathrm{g} \mathrm{cm}^{-3} \\
\text { (Relative Density) }\end{array}$} & \multicolumn{2}{|c|}{ Mean grain size } & \multirow{2}{*}{$\begin{array}{c}\text { Hardness } \\
\qquad(H V) \\
\text { / GPa }\end{array}$} & \multirow{2}{*}{$\begin{array}{c}\text { Young's } \\
\text { Modulus } \\
(E) \\
\text { / GPa }\end{array}$} & \multirow{2}{*}{$\begin{array}{c}\text { Fracture } \\
\text { Toughness }\left(K_{I c},\right. \\
/ \mathbf{M P a} \mathbf{m}^{-1 / 2}\end{array}$} \\
\hline & & $\begin{array}{l}\mathrm{Al}_{2} \mathbf{O}_{3} \\
/ \mu \mathbf{m}\end{array}$ & $\begin{array}{l}\mathrm{ZrO}_{2} \\
/ \mathbf{n m}\end{array}$ & & & \\
\hline Alumina & $\begin{array}{c}3.9 \pm 0.02 \\
(98.8 \pm 0.5 \%)\end{array}$ & $1.18 \pm 0.54$ & - & $19.31 \pm 0.16$ & 380 & $4.0 \pm 0.3$ \\
\hline nZTA & $\begin{array}{c}4.15 \pm 0.02 \\
(98.9 \pm 0.6 \%)\end{array}$ & $0.99 \pm 0.32$ & $210 \pm 35$ & $19.19 \pm 0.17$ & 355 & $5.2 \pm 0.6$ \\
\hline
\end{tabular}

\subsection{Depth of Penetration Measurements}

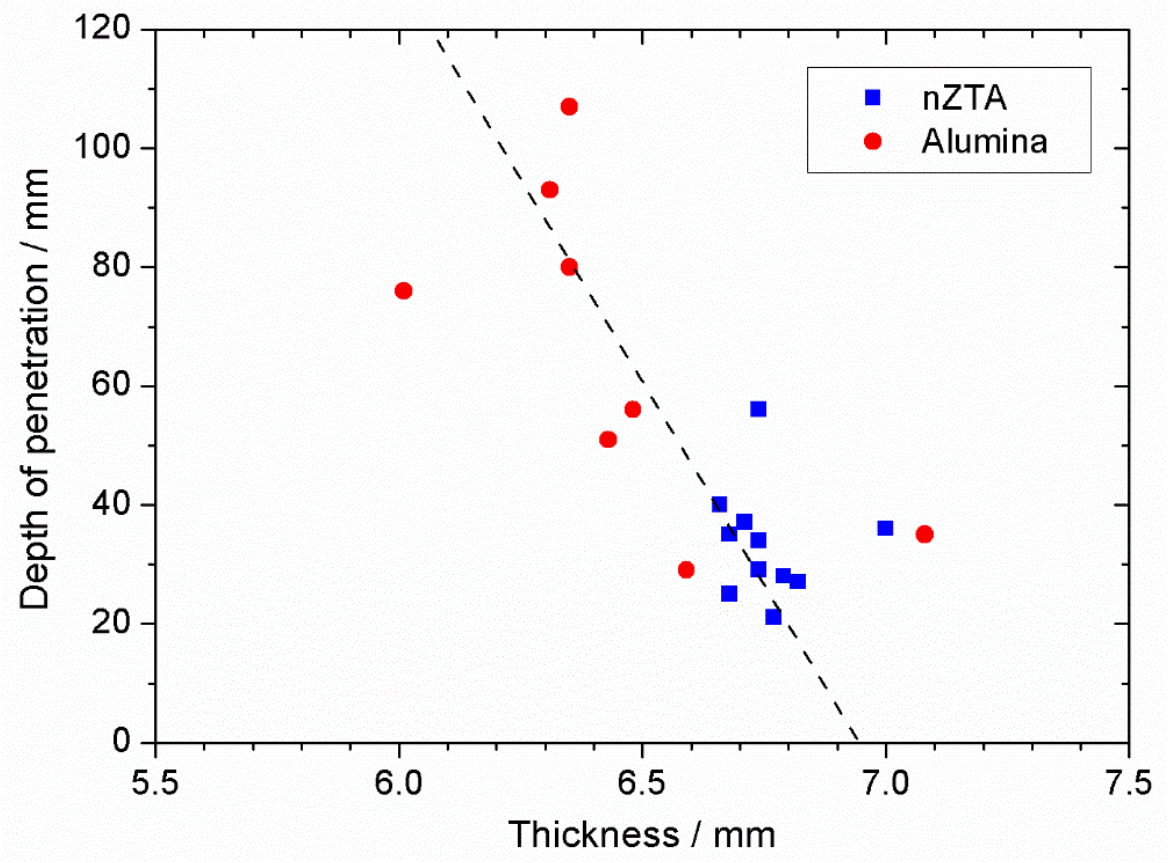

Fig. 3: Depth of penetrations achieved by projectiles after ballistic impact with nZTA and alumina targets of varying thicknesses.

DOP measurements of the ballistic tested nZTA and alumina ceramics are plotted as a function of ceramic target thickness in Fig. 3. The results show thicker targets yield lower DOP values in both materials. This is a trend that is consistent with the work of Savio et al., who demonstrated a decline in DOP with increasing ceramic target thickness in both ZTA and alumina ceramics across a thickness range of $3-6 \mathrm{~mm}$, equating this result to an increase in projectile break-up [15]. Incidentally, an examination of all the recovered projectiles in this study revealed no marked difference in the nature of 
the damage sustained. It is worth noting, however, that sequential differences in tile thickness of the nZTA and alumina ceramics in this study are considerably smaller $(\leq 0.1 \mathrm{~mm})$ compared to those in Savio et al. $(\sim 1 \mathrm{~mm})$ and so differences in terms of projectile break-up are likely to be subtle and difficult to correlate. The majority of DOP values for nZTA coalesce around a small region at $\sim 30 \pm 10$ $\mathrm{mm}$ and a target thickness of $6.75 \pm 0.05 \mathrm{~mm}$. Conversely, the alumina displays a wide range of DOP values from $\sim 29-107 \mathrm{~mm}$ across target thicknesses of $6.5 \pm 0.5 \mathrm{~mm}$. Overall, differences between the nZTA and the alumina targets in terms of the change in DOP with sample thickness are not deemed to be statistically significant, with the data points of both ceramics falling along the same trend line after the removal of anomalies (dictated by microstructural inhomogeneities). This is also in agreement with the findings of Savio et al. [15].

\subsection{Analysis of Recovered Ceramic Fragments}

\subsubsection{Size Distribution of Recovered Fragments}

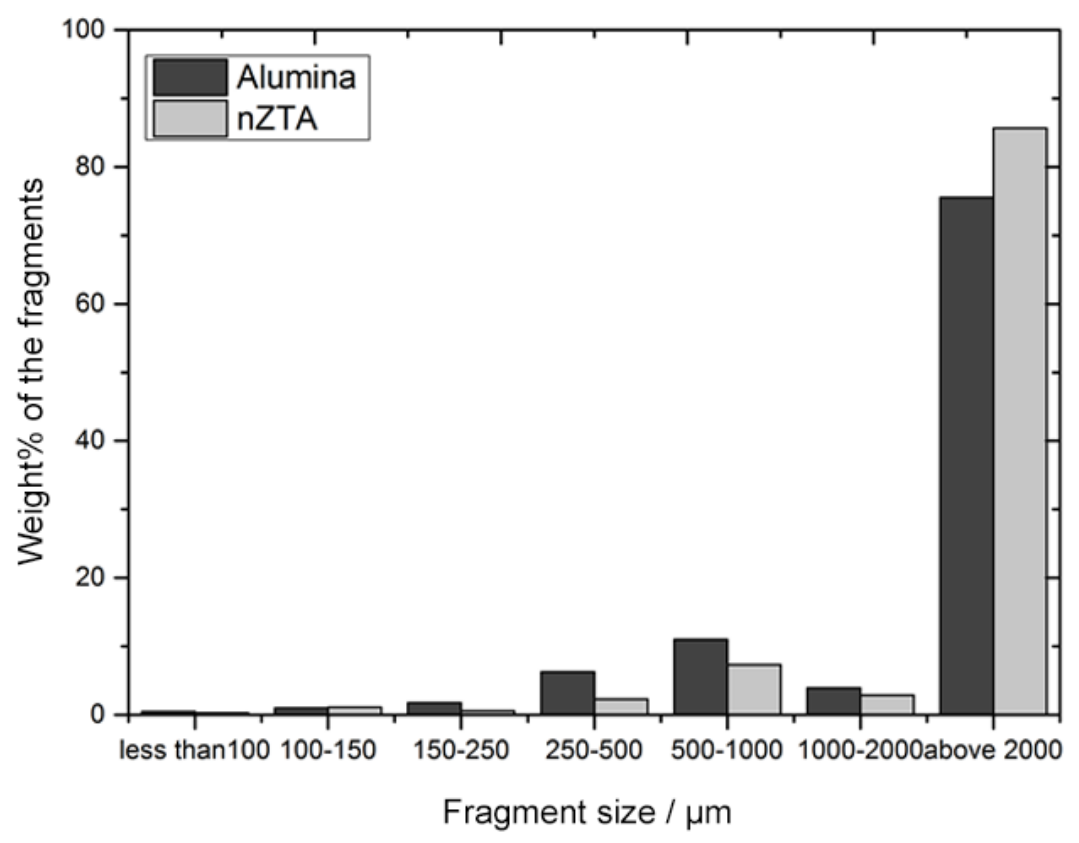

Fig. 4: Size distribution of fragments generated during ballistic testing in nZTA and alumina.

The size distribution of the fragments recovered from the nZTA and alumina targets tested is presented in Fig. 4, with corresponding values listed in Table 3. For both ceramics, $\sim 80 \%$ of the wt $\%$ of fragments generated during ballistic testing were $>2000 \mu \mathrm{m}$ in size. A comparison of the two ceramics reveals that differences in the weight percentage (wt $\%$ ) of the fragments at each of the different size ranges was small. The most significant difference was in the $>2000 \mu \mathrm{m}$ size range, where the $\mathrm{wt} \%$ of fragments produced was $\sim 14 \%$ higher in the nZTA compared to the alumina. Although a $12 \%$ difference was also 
seen in the $100-150 \mu \mathrm{m}$ size range, in all the other size ranges the alumina produced more fragments than the nZTA. As discussed below, however, not all fragment sizes are believed to be significant contributors in the erosion of the projectile and, thus, the overall ballistic performance of these two ceramics.

Table 3: Weight percentage of ballistically-generated fragments as a function of size range.

\begin{tabular}{|c|c|c|c|c|c|c|c|}
\hline & \multicolumn{7}{|c|}{ Weight percentage of fragments / \% } \\
\hline & $<100 \mu \mathrm{m}$ & $\begin{array}{c}100-150 \\
\mu \mathrm{m}\end{array}$ & $\begin{array}{c}150-250 \\
\mu \mathrm{m}\end{array}$ & $\begin{array}{c}250-500 \\
\mu \mathrm{m}\end{array}$ & $\begin{array}{c}500-1000 \\
\mu \mathrm{m}\end{array}$ & $\begin{array}{c}1000-2000 \\
\mu \mathrm{m}\end{array}$ & $>2000 \mu \mathrm{m}$ \\
\hline nZTA & 0.31 & 1.14 & 0.61 & 2.29 & 5.34 & 2.86 & 87.7 \\
\hline alumina & 0.47 & 1 & 1.79 & 6.25 & 11.01 & 3.94 & 75.5 \\
\hline
\end{tabular}

3.3.2 Zirconia Phase Transformation in Recovered Fragments

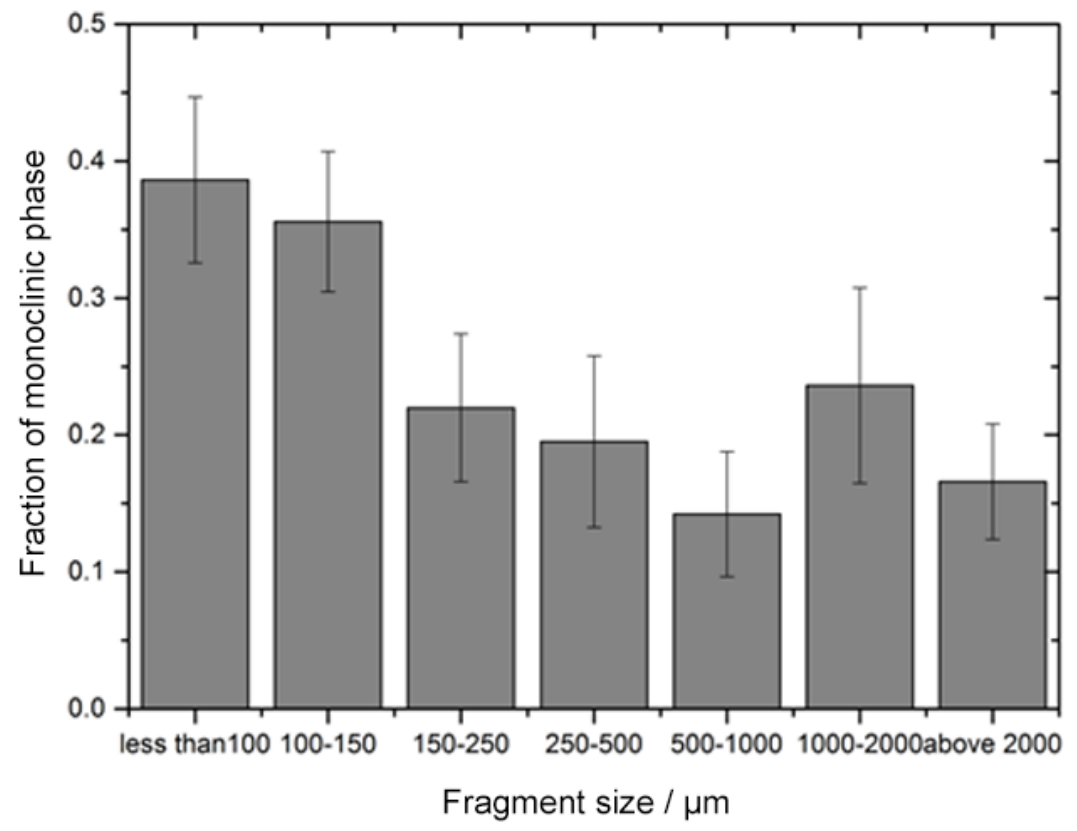

Fig. 5: The concentration of transformed monoclinic zirconia in the nZTA fragments as a function of size range.

Figure 5 shows the concentration of monoclinic zirconia phase in the nZTA fragments as a function of the different fragment size ranges. The results show that the $t-m$ phase transformation of zirconia has been activated in the high-strain rate impacts experienced during ballistic testing and occurs readily on the surface of fragments at all size ranges. It can also be seen that the amount of monoclinic transformation is dependent on the size of the fragments. Finer fragments, $<150 \mu \mathrm{m}$ in size, exhibit the most significant amount of phase transformation, up to $38 \%$ monoclinic phase, while those from $150-$ 
$2000 \mu \mathrm{m}$ show around $15-20 \%$ monoclinic phase. The phase transformation of zirconia can be promoted by the presence of both tensile and shear stresses $[9,23,24]$, therefore, in ballistic-impacted nZTA ceramics, higher amounts of monoclinic phase were to be expected in the comminuted zone closest to the projectile-target contact. The results in Fig. 5 suggest that this region was made up of the finest fragments, $<150 \mu \mathrm{m}$, a finding that is in agreement with Grady's model [8]. Meanwhile, it is likely that coarser fragments, $>150 \mu \mathrm{m}$, were generated outside the region of principle contact, as indicated by the lower and largely comparable amount of monoclinic phase at their surfaces.

\subsubsection{Alumina Surface Residual Stress and Plastic Deformation in Recovered Fragments}

Surface residual stress and plastic deformation of the alumina grains of the nZTA and pure alumina fragments as a function of their size range were analysed by $\mathrm{Cr}^{3+}$ fluorescence peak shift and peak broadening, respectively. The results are presented in Fig. 6(a-b) and show that the both ceramics exhibited similar degrees of average peak shift and broadening across the entire fragment size range, with values increasing as a function of reducing fragment size. For the fragments $>250 \mu \mathrm{m}$ in size, the degree of peak shift and broadening detected was effectively near-zero, indicating that very limited amounts of residual stress and plastic deformation had been introduced during ballistic testing. Conversely, for the fragments $<250 \mu \mathrm{m}$ in size, the average peak shift and broadening values increased considerably with a decrease in fragment size. In the nZTA, fragments sized between $150-250 \mu \mathrm{m}$ exhibited an average peak shift and broadening of -1.42 and $0.53 \mathrm{~cm}^{-1}$, respectively, corresponding to an estimated biaxial compressive stress of $281 \mathrm{MPa}$ and dislocation density of $1.4 \times 10^{12}$. In the finest nZTA fragments, $<100 \mu \mathrm{m}$, the estimated biaxial compressive stress and dislocation density increased to $1910 \mathrm{MPa}$ and $1.1 \times 10^{15}$ respectively. These values were slightly lower than those recorded in the alumina ceramic in the same $<100 \mu \mathrm{m}$ fragment size range.

It is interesting to note that the increase in the peak shift and broadening with reducing fragment size forms a similar trend to that of the monoclinic content of the zirconia particles displayed in Fig. 5. Since the activation of dislocation movement requires a shear stress that is higher than the critical shear stress for dislocation slip [25], the results in Fig. 6(a-b) provide further evidence that the fragments sized $<150$ $\mu \mathrm{m}$ were generated in the comminution (pulverisation) zone directly beneath the projectile-target contact. Here, the presence of a very high shear stress will have promoted the zirconia $t-m$ phase transformation, as well as the generation of dislocations through slip at the surface of the fragments. These damage processes are likely to have occurred principally upon impact during the $d$ well phase. However, additional dislocations, without $t-m$ transformation, may have been introduced during subsequent fragment grinding as the projectile tip was eroded during the penetration phase. Across the $150-250 \mu \mathrm{m}$ fragment size range, the detection of dislocations corresponds with a considerable drop in the monoclinic phase content, Fig. 5. Therefore, it is suspected that these fragments were generated 
at the boundary between the comminution zone and the surrounding fracture area. Meanwhile, given the limited amount of residual stress and dislocations recorded, fragments sized $>250 \mu \mathrm{m}$ are believed to have originated from an elastic region beyond the comminution zone [14]. These fragments should form solely through fracture processes that facilitate the $t-m$ phase transformation without the activation of dislocation slip, likely the propagation of radial, cone and spall cracks about the point of principal contact [26].

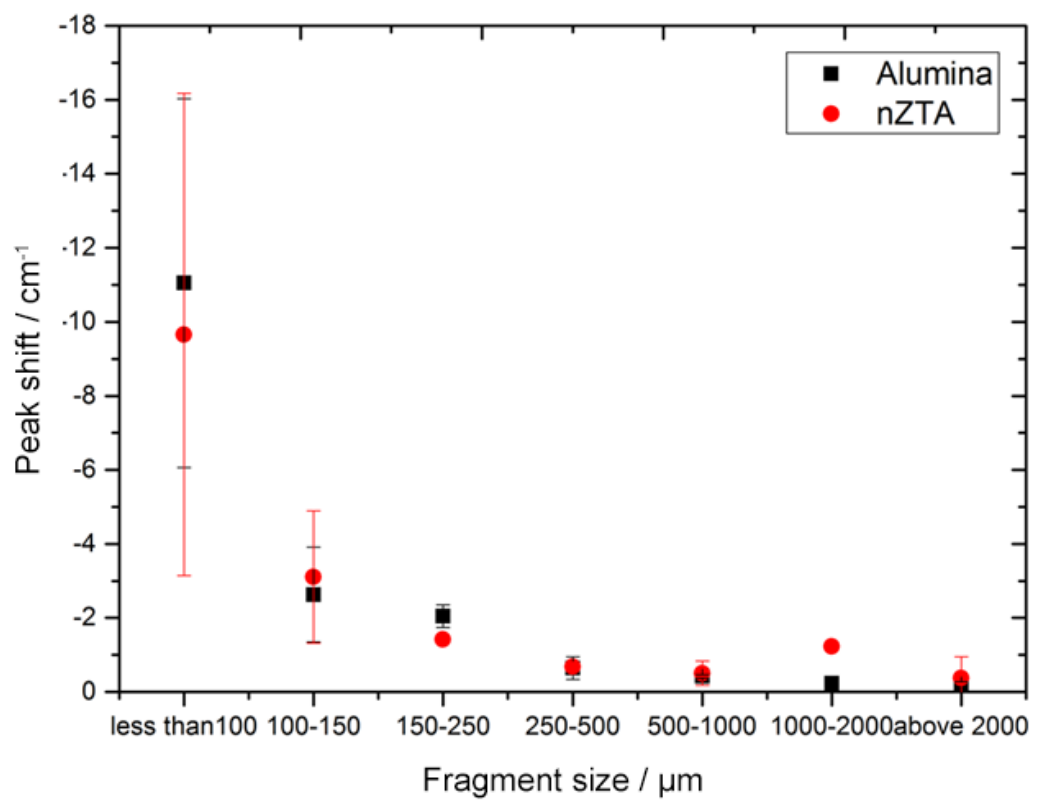

(a)

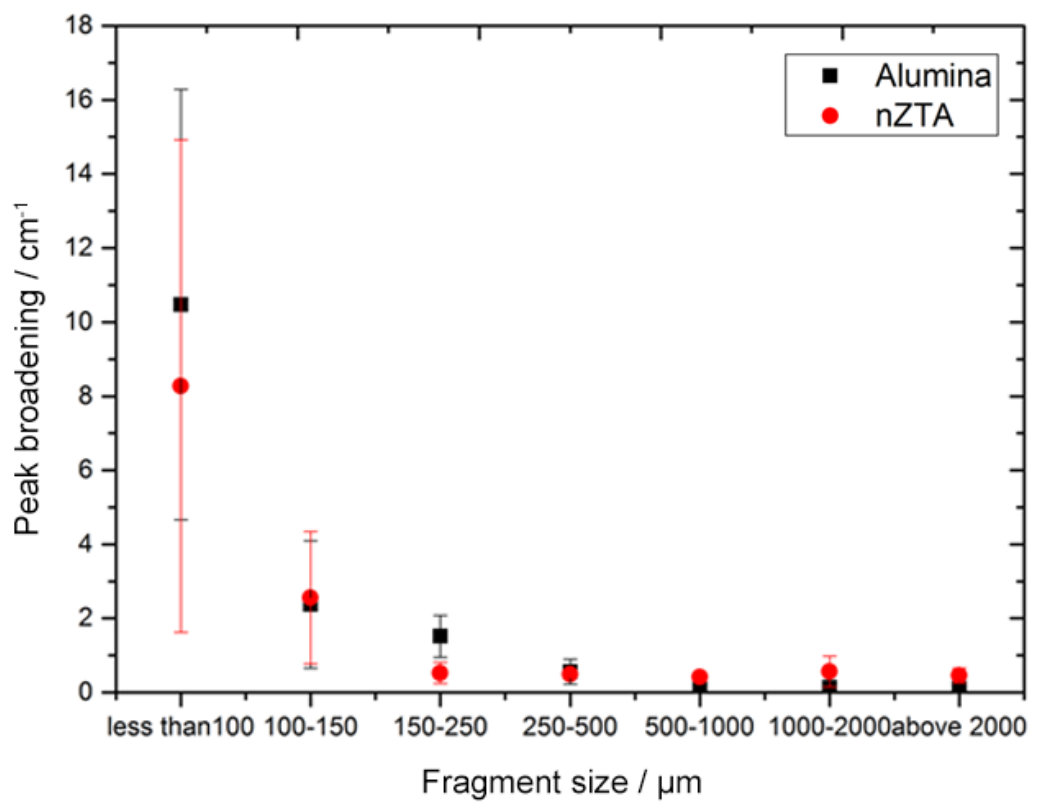

(b) 
Fig. 6: $\mathrm{Cr}^{3+}$ fluorescence R1 peak analysis of the alumina grains in the nZTA and alumina fragments generated during ballistic testing as a function of size range: (a) peak shift - a measure of residual stress, and (b) peak broadening - a measure of dislocation density.

\subsubsection{SEM and TEM observations of nZTA fragments}

(c)

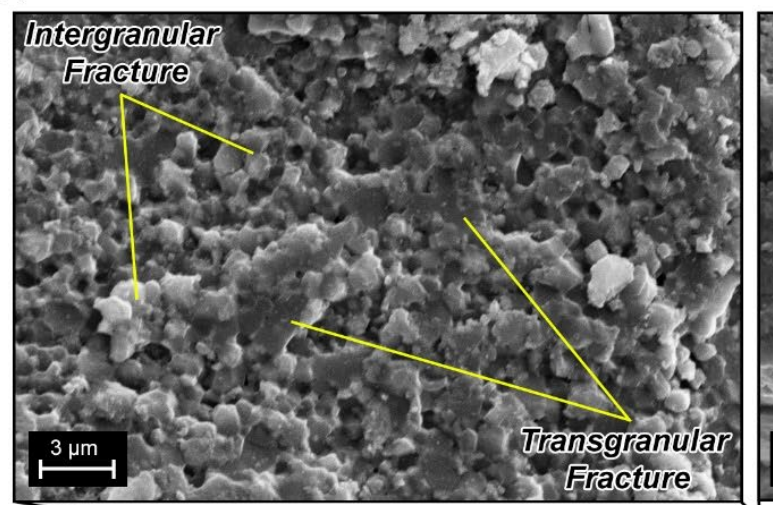

(d)

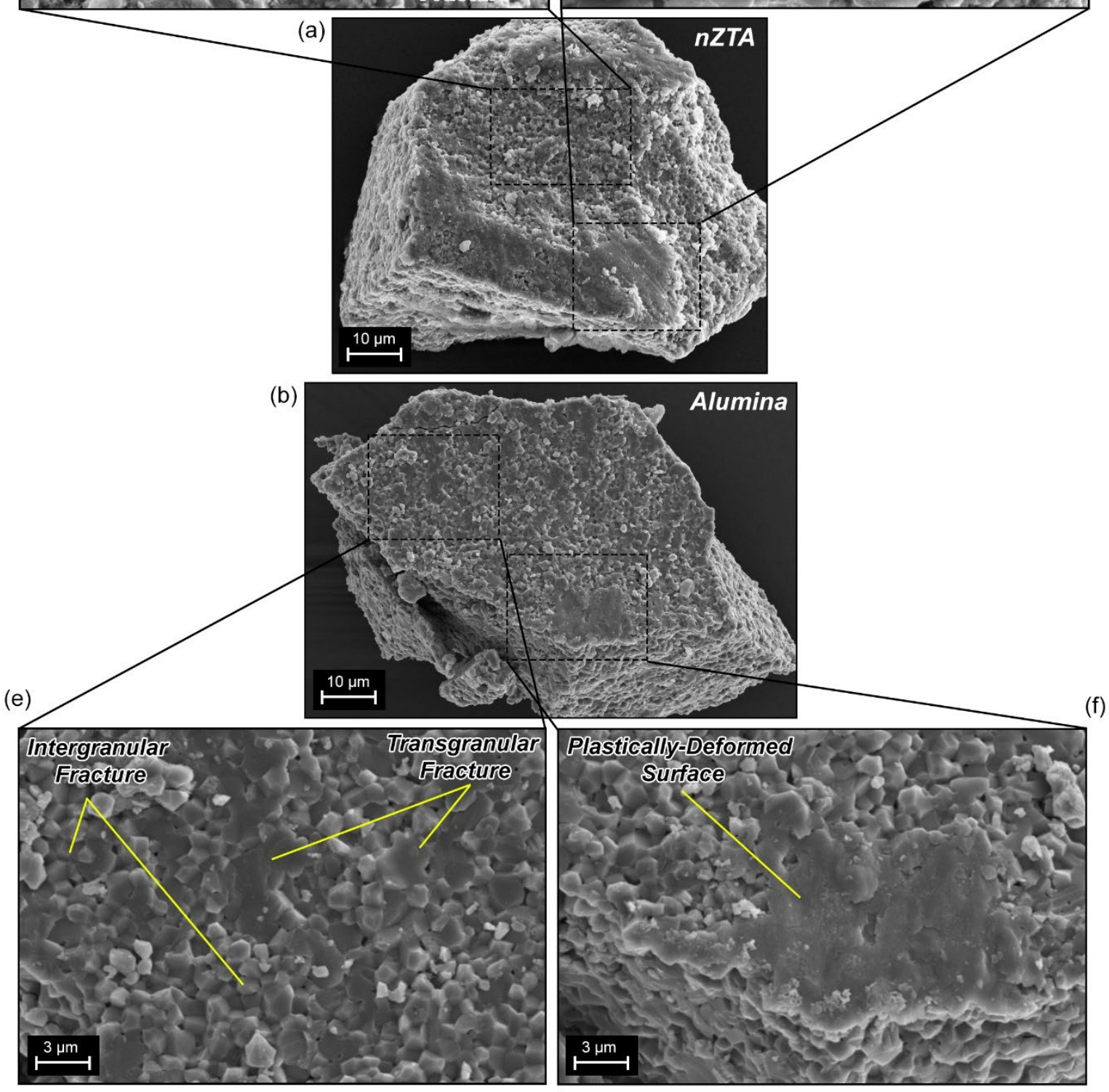


Fig. 7: SEM images of the surface of fragments $<150 \mu \mathrm{m}$ in size for: (a) nZTA, and (b) alumina, the higher magnification images in (c-d) and (e-f) highlighting the presence of surface morphologies corresponding with intergranular fracture, transgranular fracture and plastic-deformation.

The damage sustained at the surface of fragments in both the nZTA and alumina ceramics is characterised by the SEM images in Fig. 7(a-f) and Fig. 8(a-d). As shown in Fig. 7(a-b), fragments $<150 \mu \mathrm{m}$ in size in both the nZTA and alumina were found to have a faceted structure with multiple sharp corners. The surfaces of these fragments were rough and had a predominately fractured morphology. Higher magnification images in Fig. 7(c) and (e) show that these surfaces consisted of mostly intergranular fracture mixed together with local regions of transgranular fracture at a ratio of $\sim 10: 1$. The mixed-modal nature of crack propagation in both ceramics under ballistic conditions is consistent with that observed under quasi-static Vickers indentation [27]. In both ceramics, these fractured regions were broken up by trace amounts of smearing, which are depicted in Fig. 7(d) and (f), an indication of extensive subsurface plastic deformation. Confirmation of this is provided in a more detailed analysis of these regions under TEM in Fig. 9(a-d). The heterogeneous distribution of these plastically deformed regions across the fragment surfaces is believed to be the cause of the high scatter in the $\mathrm{Cr}^{3+}$ fluorescence analysis of these fragments in Fig. 6. Peak shift and broadening values measured by this technique are an average of the contributions made by the plastically-deformed and fractured regions. Whilst fractured surfaces will not cause any peak shift and broadening, plastically-deformed regions will yield high peak shifts and broadening. Consequently, differing contributions from these regions to the measurement will cause significant scattering in the final values.

SEM analysis was also performed on fragments $>250 \mu \mathrm{m}$ in Fig. 8 (a-d). These fragments did not exhibit the same smeared texture identified at the surface of the finer fragments in Fig. 7(a-f) and, instead, are found to have an exclusively fractured surface morphologies. This is true for fragments from both the nZTA and alumina ceramics and is in agreement with the assumption that these fragments are generated outside the comminution zone and solely through fracture processes. No change in the ratio of intergranular to transgranular fracture was noted, nor was there a marked difference in the shape of these larger fragments. 
(a)

(b)

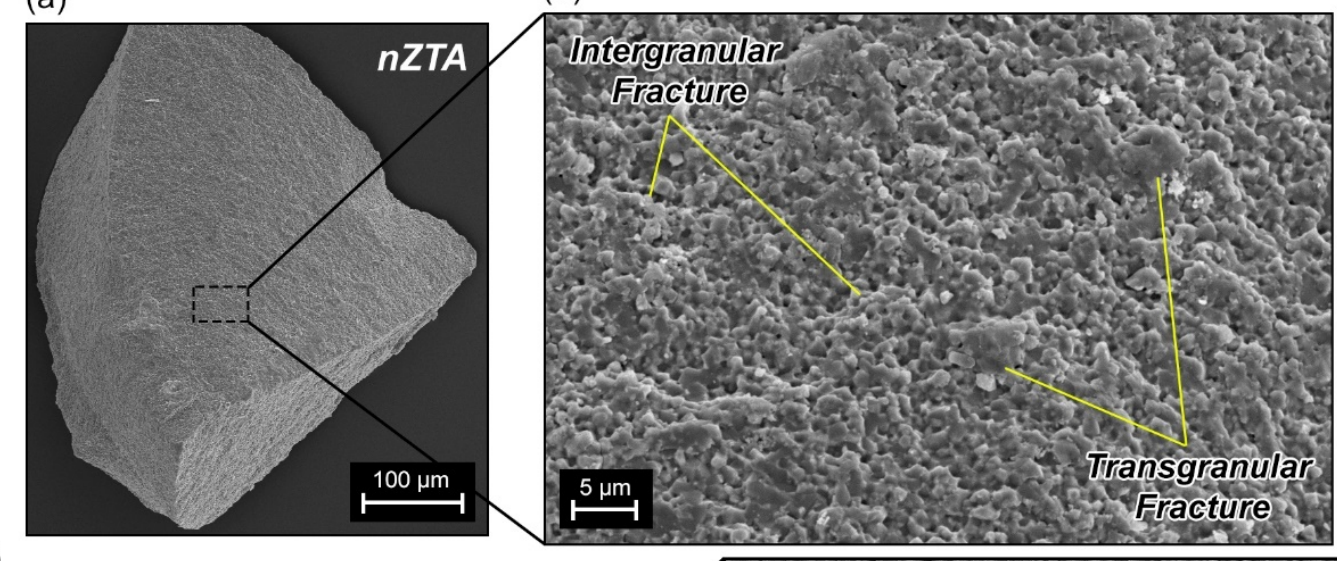

(d)

(c)
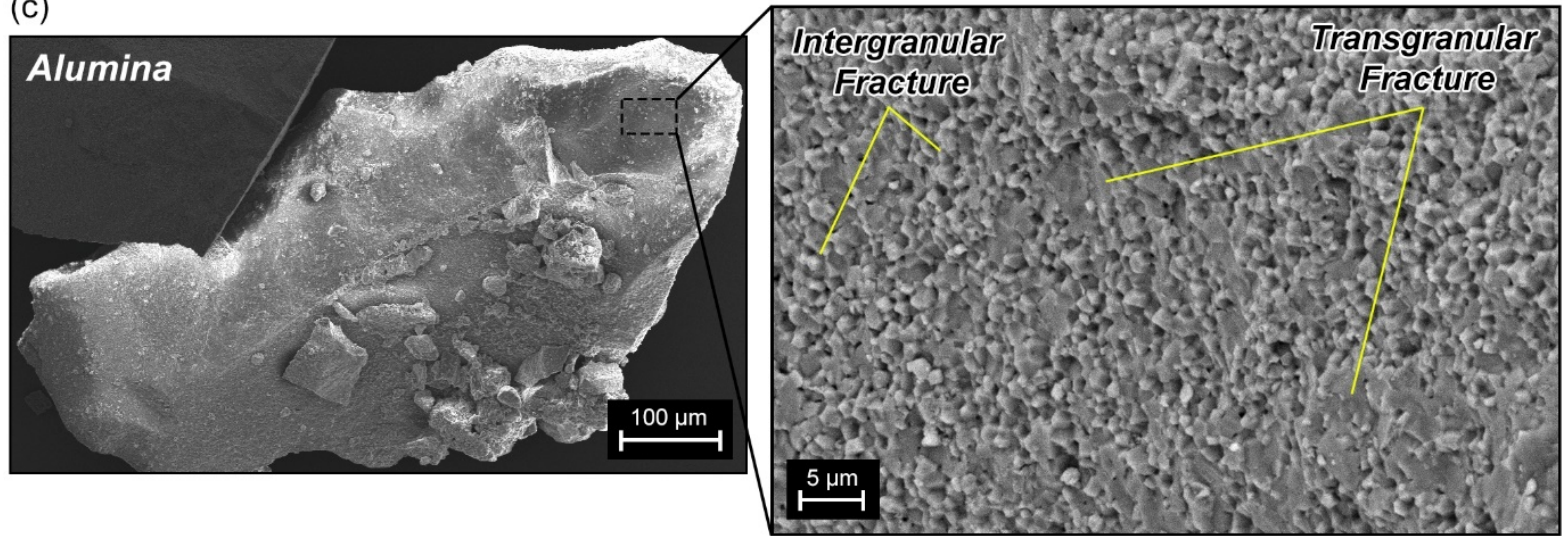

Fig. 8: SEM images of the surface of fragments $>250 \mu \mathrm{m}$ in size for: (a) nZTA, and (b) alumina, the higher magnification images in (c) and (d) demonstrating the presence of a purely fractured surface morphology corresponding with predominately intergranular fracture along with minor regions of transgranular fracture.

In order to examine and compare the subsurface damage sustained by fragments, a detailed TEM analysis was performed on both nZTA and alumina fragments of varying sizes. Figure 9(a-d) presents the TEM images of the cross-section of the smeared surface regions found in fragments $<150 \mu \mathrm{m}$ in size. As shown in Fig. 9(a) and (c), this smeared surface texture corresponds with a dislocation-rich layer at the subsurface, a finding that was consistent in both the nZTA and alumina fragments. The density of dislocations was at its highest nearest the fragment surface with them appearing to originate mostly from the alumina grain boundaries. Dislocations were also observed in the zirconia grains within the dislocation-rich layer and these grains, as well as those just outside the dislocation-layer, also often contained monoclinic twin boundaries characteristic of the $t-m$ phase transformation [28]. 

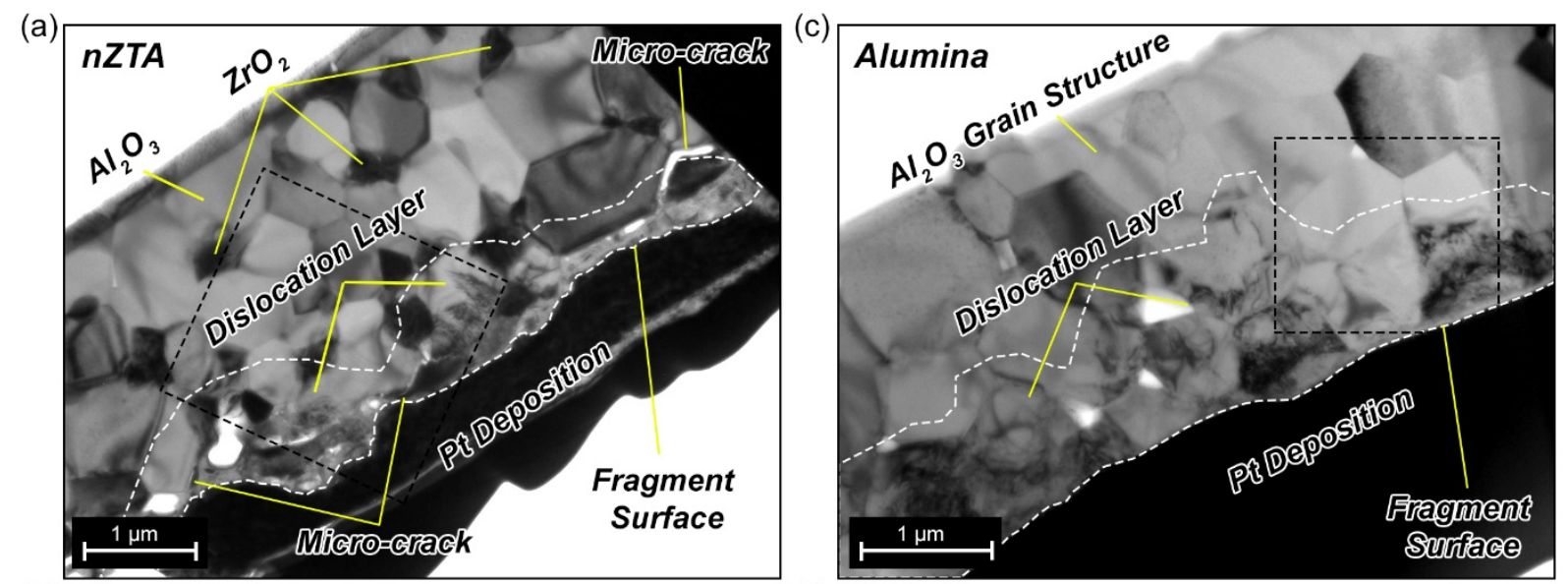

(b)

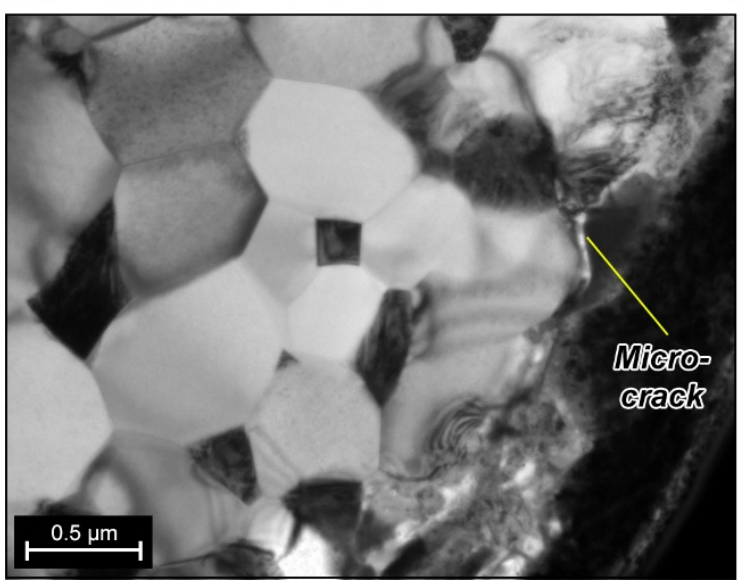

(d)

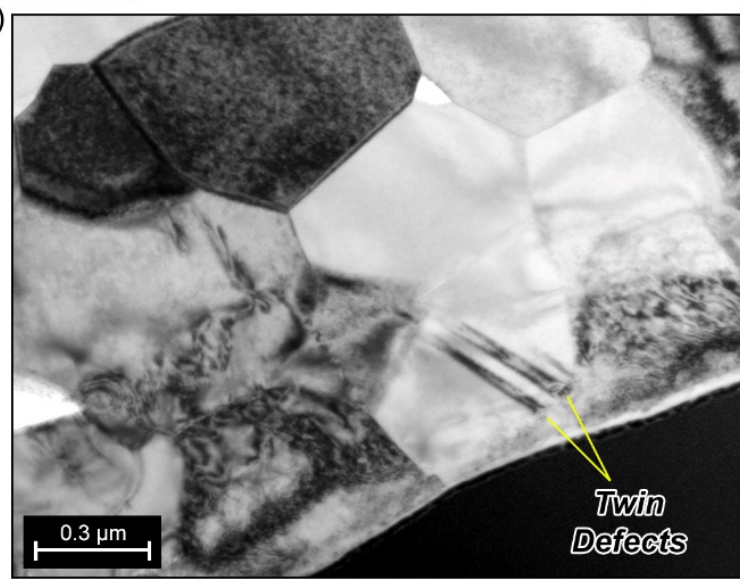

Fig. 9: TEM images of subsurface damage in fragments sized $<150 \mu \mathrm{m}$ in: (a-b) nZTA, and (c-d) alumina. The area inside the dashed yellow lines highlights a layer of dense dislocations near the fragment surface. The dashed black boxes show the area in which the higher magnificent images in (c) and (d) were taken.

In the nZTA, the high density of dislocations nearest the fragment surface lead to the formation of subgrains and grain boundary micro-cracks that developed to relieve stress, see Fig. 9(a). Meanwhile, in the alumina ceramic, twin defects were observed, see Fig. 9(d). Based on previous work on dynamic plasticity in alumina, it is likely that these are basal twins (0001) [29,30]. Similarly, whilst most dislocations were likely to have been basal dislocations (0001) with Burgers vectors of the types $<10$ Error! Bookmark not defined. $\overline{1} 0>$ and $1 / 3<11$ Error! Bookmark not defined. $\overline{2} 0>$ and glide along basal slip planes, some may have also been non-basal dislocations [31]. At locations deeper into the subsurface of both the nZTA and alumina fragments, the dislocation density was found to gradually decrease, with no dislocations detected beyond a depth of $\sim 1 \mu \mathrm{m}$. This dislocation layer thickness was less than that observed after quasi-static indentation [32], subsurface plasticity in alumina reportedly capable of penetrating up to $\sim 5 \mu \mathrm{m}$ below the surface [33,34]. Such a finding would suggest that, under dynamic conditions, the plastic deformation observed in the nZTA and alumina fragments has been constrained to only the surface grains. 

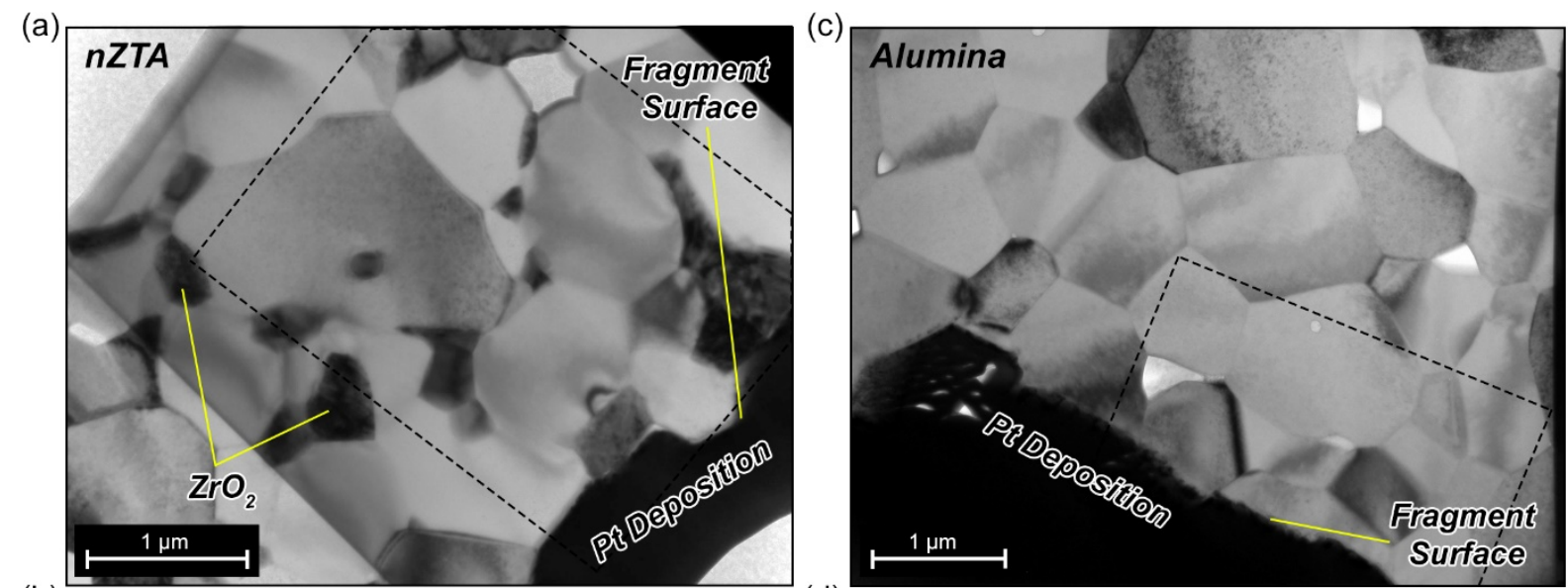

(b)

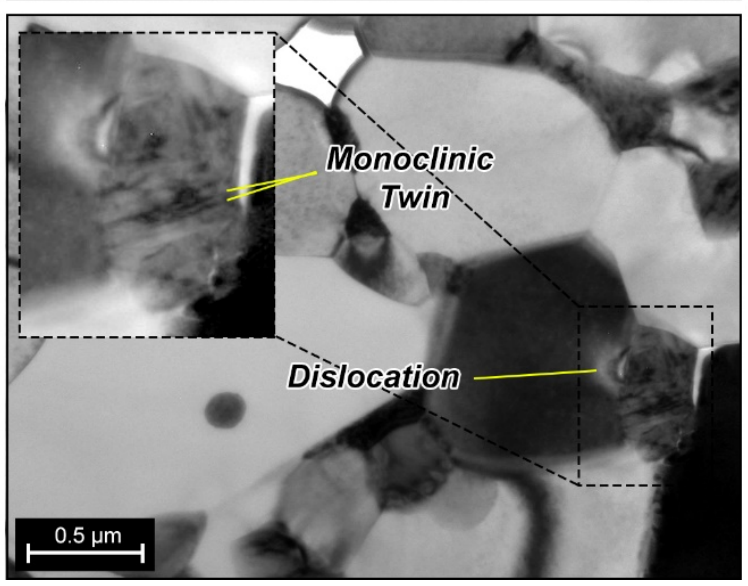

(d)

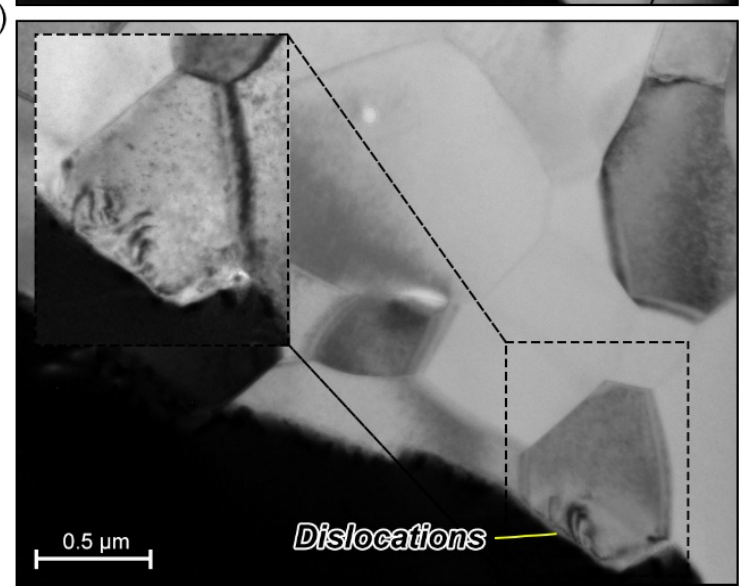

Fig. 10: TEM images of subsurface damage in fragments sized $>150 \mu \mathrm{m}$ in: (a-b) nZTA, and (c-d) alumina. Note, there are no dislocations visible at the surface of fragments in either ceramic. The dashed black boxes show the area in which the higher magnificent images in (c) and (d) were taken.

The TEM images in Fig. 10(a-d) are cross-sections of the surface of both nZTA and alumina fragments $>150 \mu \mathrm{m}$ in size. In the absence of a smeared surface texture on these larger fragments, TEM lift-outs were taken from the intergranular and transgranular fracture surfaces. As demonstrated in Fig. 10(b) and (d), the subsurface of these regions in either ceramic were found to contain only a few dislocations with no micro-cracks. These dislocations were only activated in the alumina grains and, in both instances, nucleated from the fragment surface boundary of an intergranular fractured grain. The presence of a dense dislocation layer in fragments $<150 \mu \mathrm{m}$ in size and only a few dislocations in fragments $>150 \mu \mathrm{m}$ in size is consistent with the $\mathrm{Cr}^{3+}$ fluorescence measurements in Fig. 6(a-b), validating the analysis and providing confidence in the conclusions drawn from those results. 


\section{Discussion}

\subsection{Ballistic Performance of nZTA and alumina}

The DOP measurements in Fig. 3 demonstrate that there is no statistically significant difference in the ballistic performance of the nZTA ceramics prepared in this investigation compared with an alumina ceramic of equivalent microstructure and mechanical / physical properties. The similar hardness and Young's modulus of the nZTA and alumina means that the blunting of the incoming projectile and subsequent $d$ well phase should remain largely the same. Therefore, an explanation for the above result may be sort by understanding the processes that influence the performance during the penetration phase. In accordance with Shockey et al's theory, the projectile penetration resistance of a material during ballistic impacts is largely determined by the comminution energy, time and flow [35]. The comminution energy is shown to only contribute to $\sim 1 \%$ of the total kinetic energy of the projectile and hence is considered negligible [35]. Therefore, the penetration resistance is primarily governed by the time required to generate fragments within the comminution zone and their frictional resistance to flow - the fragments need to be moved aside as penetration deepens. The former is determined by the impact speed of the projectile and the shear wave velocity of the ceramic, which is comparable to the terminal crack propagation velocity. Measurements extracted from the literature show that shear wave velocities of alumina and nZTA are between $5500-6500 \mathrm{~ms}^{-1}$ [36]. These values are consistent with recently measured average crack speeds in alumina during impact testing [37]. The comparable shear wave velocities would suggest both materials should experience similar comminution times upon ballistic impact. Therefore, differences in the ballistic performance of the nZTA and alumina ceramics, if any, are likely to come from changes in the resistance to fragment flow, which is related to the fragment size and geometry. From Grady's equation in eq. (1), it is estimated that the average size of fragments in the nZTA should be $\sim 20-25 \%$ larger than those of the alumina ceramic. The most important fragment sizes are those that originate within the comminution zone, which, as confirmed by the Raman, $\mathrm{Cr}^{3+}$ fluorescence and TEM analysis above, is found to be those sized $<150 \mu \mathrm{m}$. However, post-impact fragment analysis in Fig. 4 reveals that the wt $\%$ of fragments $<150 \mu \mathrm{m}$ in size is relatively similar in both the nZTA and the alumina ceramic. In fact, the alumina is found to have a higher wt $\%$ of fragments at every measured size range $>150 \mu \mathrm{m}$ until the nZTA takes over at fragments sized $>2000 \mu \mathrm{m}$. This would suggest that there is no significant change in the size of the fragments generated in the nZTA compared to the alumina, particularly at sizes relevant to comminution processes. Without an increase in the size of ceramic fragmentation, there is unlikely to be an appreciable improvement in the ballistic performance of the nZTA. 


\subsection{Transformation Toughening under Ballistic Conditions}

In demonstrating that there is no change in the size of ceramic fragmentation during ballistic impacts, it may be concluded that the increased $K_{I c}$ of the nZTA compared to alumina has not had an appreciable effect on the ballistic performance. The reason for this remains somewhat unclear. From Fig. 5, it is evident that the $t-m$ zirconia phase transformation has occurred, the peak amount of monoclinic zirconia phase being $38 \%$ in fragments $<100 \mu \mathrm{m}$ in size generated within the comminution zone. This result, however, equates to approximately half the percentage of phase transformation measured in Vickers indents used to calculate the $K_{I c}(\sim 70 \%)$ [32]. Much higher monoclinic zirconia phase concentrations of between $\sim 80-95 \%$ have also been reported in $10 \%$ zirconia ZTA ceramics after quasi-static indentation and dynamic gas gun tests [38]. The lower amounts of monoclinic zirconia phase within the ballistically-generated nZTA fragments provides an indication that the effectiveness of the transformation toughening is reduced in these high strain-rate situations. Note that as the projectile penetrates deeper into the material, it will interact with fragments $>100 \mu \mathrm{m}$ in size. These are shown to contain even lower fractions of monoclinic phase, as low as $15 \%$, an indication of even less transformation toughening. This reduction in the amount of monoclinic zirconia phase may stem from the transient nature of loading under ballistic conditions, with peak contact stresses typically being applied for 10s of $\mu \mathrm{s}$. Evidence of these transient effects can be seen from the TEM images in Fig. 9(ad), where the temporal activation of slip has limited the mobility of dislocations to short distances away from their source grain boundaries [29]. The reduced effectiveness of transformation toughening in the nZTA ceramic may result in the material having a dynamic fracture toughness, $K_{I d}$, that is closer to the alumina than the $K_{I c}$ measured under quasi-static conditions. Previous measurements by Kishi [39] have demonstrated similar increases in $K_{I d}$ as a function of strain rate (up to $10^{6} \mathrm{~s}^{-1}$ ) in both $3 \%$ yttria stabilised tetragonal zirconia polycrystal (TZP) and alumina. However, further work is needed to conclusively demonstrate this in ZTA ceramics.

\subsection{A Comparison of Prior Ballistic Experiments on ZTA}

The results presented in this study are found to be consistent with the work of Savio et al. [15], but contradictory to the findings of Zhang and Li [14]. It is speculated that this is due to the similarities / differences in testing setups employed, as well as control over the microstructure of the ZTA and alumina. For example, Savio et al. performed largely analogous experiments to the ones performed in this paper, using the same $7.62 \mathrm{~mm}$ armour piercing hardened steel core. Projectile velocities were slightly slower than those used here $\left(810-818 \mathrm{~ms}^{-1}\right)$, but above the upper limit at which damage propagation rates have been shown to plateau $\left(\sim 700 \mathrm{~ms}^{-1}\right)$ [40], i.e. the comminution time should have 
been the same. Conversely, Zhang and Li used LRP tests to evaluate the performance of ZTA ceramics. The LRPs used were made of tungsten, much longer in length $(110 \mathrm{~mm})$, and had a flat tip. This change in tip geometry will provide an alternate stress condition to the one experienced by the materials in this study, and that of Savio et al., changing the fracture pattern and pathways generated underneath the impact area and, possibly, the type and prevalence of the individual damage modes experienced (e.g. intergranular / transgranular fracture, twin deformation, dislocation slip, etc.) [41]. The higher impact velocities of the LRP tests (1100-1500 $\left.\mathrm{ms}^{-1}\right)$ may also introduce hydrodynamic penetration effects, which typically appears at velocities $>1150 \mathrm{~ms}^{-1}$, and, at equivalent projectile lengths, are governed by projectile-target density ratios, which will differ in ZTA and alumina. However, experimental results have demonstrated that, even at the peak impact velocity of $1520 \mathrm{~ms}^{-1}$ used by Zhang and Li, penetration velocities of LRPs are $<50 \%$ of the hydrodynamic limit in alumina. Thus, it is unlikely that these effects will have a significant contribution. Another consideration is the increased hardness of tungsten (3.5 $5 \mathrm{GPa}$ ) compared to hardened steel (1.2 - 3.9 GPa), which will influence the contribution that ductile deformation processes at the projectile tip make to the overall defeat procedure, perhaps shifting the ballistic performance of the ceramics tested to be more dependent on the erosion effects during penetration. In terms of materials tested, the experiments of Savio et al. were performed on high purity (99.5\%) and high density (>98\%) ZTA and alumina ceramics. Equivalent values of hardness provide at least some indication that the microstructure of the ZTA and alumina used in their experiments were of comparable grain size. Meanwhile, the ZTA and alumina ceramics used by Zhang and Li were low purity (95\%), containing significant quantities of sintering aids, and low density ( $\sim 8-9 \%$ porosity) materials. The former indicates the use of liquid phase sintering, which has been shown by Huang et al. [42] to promote the growth of large and abnormal grains in alumina but to have a limited coarsening effect in ZTA due to zirconia grain boundary pinning effects [43]. If not carefully controlled, this could lead to significant differences in the grain structure of each ceramic, which, along with differences in the amount of porosity and impurities, has been shown to have a significant influence on ballistic performance $[4,37,44]$. In addition to changing core mechanical / physical properties, pores, weak glassy-phases and grain boundary sites are defects from which fracture may readily propagate during ballistic contacts. Consequently, the increased size and preponderance of these features will lead to earlier initiation of fracture, reducing the $d$ well phase time such that the overall ballistic performance suffers. Considering that only limited information was provided by Zhang and Li regarding the fabrication of the ceramics tested and their subsequent microstructures, it is difficult to rule out microstructural inconsistencies between the two ceramics tested as a potential cause for the improved ballistic performance displayed by the ZTA ceramic. From this it may be concluded that, for the purpose of comparing the results of ballistic experiments, it is important to not only list the testing procedures employed, but to also provide a detailed microstructural analysis of the ceramics being tested, even on notionally the same ceramic composition. 


\section{Conclusions}

In this investigation, prepared nZTA and alumina ceramics of equivalent physical and mechanical properties, aside from a $30 \%$ increase in $K_{I c}$ in the nZTA, have been subjected to ballistic testing in order to evaluate the potential of transformation toughening as a means of improving the defeat capabilities of armour alumina. The present findings found no statistically significant difference in the ballistic performance of the nZTA compared with the alumina control. This is attributed to the fact that, despite having a much higher $K_{I c}$, the nZTA produced fragments of comparable sizes and quantities to those in the alumina. Raman, $\mathrm{Cr}^{3+}$ fluorescence and TEM analysis shows that fragments $<150 \mu \mathrm{m}$ in size were almost certainly generated in the comminution zone during the ballistic impacts and played the most significant role in determining the ballistic performance. These fragments were found to contain high levels of residual stress, high dislocation densities and up to $38 \%$ monoclinic zirconia phase. It is proposed that, although the $t-m$ zirconia phase transformation is active during ballistic impacts, the transient loading conditions means that its effectiveness is reduced. This is believed to result in the nZTA having a dynamic fracture toughness, $K_{I d}$, that is closer to the alumina than the $K_{I c}$ measured under quasi-static conditions, thus, inhibiting any transformation toughening-induced improvements in ballistic performance. Dissimilarities between the results of this work and those of prior experiments in the literature are speculated to be the result of differences in the test procedures employed and, potentially, microstructural inconsistencies between the ZTA and alumina ceramics tested.

\section{Acknowledgement}

The authors gratefully acknowledge the funding support from EPSRC, Defence Science and Technology Laboratory (DSTL) and the Ministry of Defence (MOD), UK under 'Understanding and Improving Ceramic Armour' (UNICAM) programme and 'Materials and Structures Technology' (MAST) programme. The authors would like to thank Mr Graham H Williams (DSTL) and Dr Jennifer DeCerbo (on assignment to DSTL from the US Air Force Research Lab) for their assistance in the ballistic testing and Neil Middleton (DSTL) for his review and comments.

\section{References}

[1] E. Medvedovski, Ballistic performance of armour ceramics: Influence of design and structure. Part 1, Ceram. Int. 36 (2010) 2103-2115. https://doi.org/10.1016/j.ceramint.2010.05.021.

[2] W.W. Chen, A.M. Rajendran, B. Song, X. Nie, Dynamic Fracture of Ceramics in Armor Applications, J. Am. Ceram. Soc. 90 (2007) 1005-1018. https://doi.org/10.1111/j.1551- 
2916.2007.01515.x.

[3] M.L. Wilkins, Mechanics of penetration and perforation, Int. J. Eng. Sci. 16 (1978) 793-807. https://doi.org/10.1016/0020-7225(78)90066-6.

[4] A. Krell, E. Strassburger, Order of influences on the ballistic resistance of armor ceramics and single crystals, Mater. Sci. Eng. A. 597 (2014) 422-430.

https://doi.org/10.1016/j.msea.2013.12.101.

[5] A. Krell, E. Strassburger, Ballistic strength of opaque and transparent armor, Am. Ceram. Soc. Bull. 86 (2007) 9201-9207.

[6] I.M. Hutchings, R.E. Winter, J.E. Field, Solid particle erosion of metals: The removal of surface material by spherical projectiles, Proc. R. Soc. A Math. Phys. Eng. Sci. 348 (1976) 379-392. https://doi.org/10.1098/rspa.1976.0044.

[7] R. Brown, S. Kosco, E.J. Jun, The effect of particle shape and size on erosion ofaluminum alloy 1100 at $90^{\circ}$ impact angles, Wear. 88 (1983) 181-193. https://doi.org/10.1016/S00431648(83)80007-6.

[8] D.E. Grady, Local inertial effects in dynamic fragmentation, J. Appl. Phys. 53 (1982) 322325. https://doi.org/10.1063/1.329934.

[9] J. Wang, R. Stevens, Zirconia-toughened alumina (ZTA) ceramics, J. Mater. Sci. 24 (1989) 3421-3440. https://doi.org/10.1007/BF02385721.

[10] M. Rühle, Microcrack and transformation toughening of zirconia-containing alumina, Mater. Sci. Eng. 105-106 (1988) 77-82. https://doi.org/10.1016/0025-5416(88)90482-X.

[11] B.L. Karihaloo, Contribution of $\mathrm{t} \rightarrow \mathrm{m}$ phase transformation to the toughening of ZTA, J. Am. Ceram. Soc. 74 (1991) 1703-1706. https://doi.org/10.1111/j.1151-2916.1991.tb07166.x.

[12] A.G. Evans, R.M. McMeeking, On the toughening of ceramics by strong reinforcements, Acta Metall. 34 (1986) 2435-2441. https://doi.org/10.1016/0001-6160(86)90146-X.

[13] S. Huang, Nanostructured advanced ceramics for armour applications, Loughborough University, 2013.

[14] X.F. Zhang, Y.C. Li, On the comparison of the ballistic performance of $10 \%$ zirconia toughened alumina and 95\% alumina ceramic target, Mater. Des. 31 (2010) 1945-1952. https://doi.org/10.1016/j.matdes.2009.10.046.

[15] S.G. Savio, V. Madhu, A.K. Gogia, Ballistic performance of alumina and zirconia-toughened alumina against 7.62 armour piercing projectile, Def. Sci. J. 64 (2014) 477-483. https://doi.org/10.14429/dsj.64.6745.

[16] S.J. Bless, S.J. Hanchak, Ballistic evaluation of ZTA and zirconia, Dayton, Ohio, 1989.

[17] G.R. Anstis, P. Chantikul, B.R. Lawn, D.B. Marshall, A critical evaluation of indentation techniques for measuring fracture toughness: I, Direct crack measurements, J. Am. Ceram. Soc. 64 (1981) 533-538. https://doi.org/10.1111/j.1151-2916.1981.tb10320.x.

[18] D.R. Clarke, F. Adar, Measurement of the crystallographically transformed zone produced by 
fracture in ceramics containing tetragonal zirconia, J. Am. Ceram. Soc. 65 (1982) 284-288. https://doi.org/10.1111/j.1151-2916.1982.tb10445.x.

[19] L. Grabner, Spectroscopic technique for the measurement of residual stress in sintered $\mathrm{Al}_{2} \mathrm{O}_{3}$, J. Appl. Phys. 49 (1978) 580-583. https://doi.org/10.1063/1.324682.

[20] H.Z. Wu, S.G. Roberts, B. Derby, Residual stress distributions around indentations and scratches in polycrystalline $\mathrm{Al}_{2} \mathrm{O}_{3}$ and $\mathrm{Al}_{2} \mathrm{O}_{3} / \mathrm{SiC}$ nanocomposites measured using fluorescence probes, Acta Mater. 56 (2008) 140-149. https://doi.org/10.1016/j.actamat.2007.09.014.

[21] K. Niihara, New design concept of structural ceramics, J. Ceram. Soc. Japan. 99 (1991) 974 982. https://doi.org/10.2109/jcersj.99.974.

[22] P. Palmero, F. Kern, F. Sommer, M. Lombardi, R. Gadow, L. Montanaro, Issues in nanocomposite ceramic engineering: Focus on processing and properties of alumina-based composites, J. Appl. Biomater. Funct. Mater. 12 (2014) 113-128. https://doi.org/10.5301/jabfm.5000185.

[23] A.H. Heuer, F.F. Lange, M. V Swain, A.G. Evans, Transformation toughening: An overview, J. Am. Ceram. Soc. 69 (1986) i-iv. https://doi.org/10.1111/j.1151-2916.1986.tb07400.x.

[24] M.J. Reece, P.L. Tetlow, C. Galiotis, Phase transformation around indentations in zirconia, J. Mater. Sci. Lett. 11 (1992) 575-577. https://doi.org/10.1007/BF00728613.

[25] D.W. Richerson, Modern Ceramic Engineering, Second Edi, Marcel Dekker Inc., 2006.

[26] D. Sherman, D.G. Brandon, The ballistic failure mechanisms and sequence in semi-infinite supported alumina tiles, J. Mater. Res. 12 (1997) 1335-1343. https://doi.org/10.1557/JMR.1997.0182.

[27] Y. Zhu, Development of alumina based ceramic nanocomposites for armour applications, Loughborough University, 2017.

[28] Q.L. Ge, T.C. Lei, J.F. Mao, Y. Zhou, In situ transmission electron microscopy observations of the tetragonal-to-monoclinic phase transformation of zirconia in $\mathrm{Al}_{2} \mathrm{O}_{3}-\mathrm{ZrO}_{2}\left(2 \mathrm{~mol} \% \mathrm{Y}_{2} \mathrm{O}_{3}\right)$ composite, J. Mater. Sci. Lett. 12 (1993) 819-822. https://doi.org/10.1007/BF00277984.

[29] M.W. Chen, J.W. McCauley, D.P. Dandekar, N.K. Bourne, Dynamic plasticity and failure of high-purity alumina under shock loading, Nat. Mater. 5 (2006) 614-618. https://doi.org/10.1038/nmat1689.

[30] C.S. Yust, L.A. Harris, Observation of dislocations and twins in explosively compacted alumina, in: M. Meyers, L. Murr (Eds.), Shock Waves Adn High-Strain-Rate Phenom. Met., Plenum, New York, 1981: pp. 881-895.

[31] Y. Wang, D.E. Mikkola, Shock deformation of sapphire single crystals, Mater. Sci. Eng. A. 148 (1991) 25-32. https://doi.org/10.1016/0921-5093(91)90862-H.

[32] S. Huang, J.G.P. Binner, B. Vaidhyanathan, R.I. Todd, Quantitative analysis of the residual stress and dislocation density distributions around indentations in alumina and zirconia toughened alumina (ZTA) ceramics, J. Eur. Ceram. Soc. 34 (2014) 753-763. 
https://doi.org/10.1016/j.jeurceramsoc.2013.09.021.

[33] B.J. Inkson, Dislocations and twinning activated by the abrasion of $\mathrm{Al}_{2} \mathrm{O}_{3}$, Acta Mater. 48 (2000) 1883-1895. https://doi.org/10.1016/S1359-6454(99)00468-1.

[34] H.Z. Wu, S.G. Roberts, G. Möbus, B.J. Inkson, Subsurface damage analysis by TEM and 3D FIB crack mapping in alumina and alumina/5vol.\%SiC nanocomposites, Acta Mater. 51 (2003) 149-163. https://doi.org/10.1016/S1359-6454(02)00387-7.

[35] D.A. Shockey, J.W. Simons, D.R. Curran, The damage mechanism route to better armor materials, Int. J. Appl. Ceram. Technol. 7 (2010) 566-573. https://doi.org/10.1111/j.17447402.2010.02509.x.

[36] H. Carreon, A. Ruiz, A. Medina, G. Barrera, J. Zarate, Characterization of the aluminazirconia ceramic system by ultrasonic velocity measurements, Mater. Charact. 60 (2009) 875881. https://doi.org/10.1016/j.matchar.2009.02.008.

[37] B.M.L. Koch, P. Jannotti, D. Mallick, B. Schuster, T. Sano, J.D. Hogan, Influence of microstructure on the impact failure of alumina, Mater. Sci. Eng. A. 770 (2020) 138549. https://doi.org/10.1016/j.msea.2019.138549.

[38] C.E.J. Dancer, J.N.F. Spawton, S. Falco, N. Petrinic, R.I. Todd, Characterisation of damage mechanisms in oxide ceramics indented at dynamic and quasi-static strain rates, J. Eur. Ceram. Soc. 39 (2019) 4936-4945. https://doi.org/10.1016/j.jeurceramsoc.2019.06.054.

[39] T. Kishi, Dynamic fracture toughness in ceramics and ceramics matrix composites, Eng. Fract. Mech. 40 (1991) 785-790. https://doi.org/10.1016/0013-7944(91)90235-S.

[40] C.E. Anderson, R.P. Bigger, C.E. Weiss, Crack and damage velocities in ballistic experiments, Int. J. Appl. Glas. Sci. 5 (2014) 374-383. https://doi.org/10.1111/ijag.12091.

[41] J.W. McCauley, E. Strassburger, P. Patel, B. Paliwal, K.T. Ramesh, Experimental observations on dynamic response of selected transparent armor materials, Exp. Mech. 53 (2013) 3-29. https://doi.org/10.1007/s11340-012-9658-5.

[42] X.W. Huang, S.W. Wang, X.X. Huang, Microstructure and mechanical properties of ZTA fabricated by liquid phase sintering, Ceram. Int. 29 (2003) 765-769. https://doi.org/10.1016/S0272-8842(02)00228-6.

[43] K. Okada, T. Sakuma, The Role of Zener's Pinning Effect on the Grain Growth in $\mathrm{Al}_{2} \mathrm{O}_{3}-\mathrm{ZrO}_{2}$, J. Ceram. Soc. Japan. 100 (1992) 382-386. https://doi.org/10.2109/jcersj.100.382.

[44] R.L. Landingham, A.W. Casey, Final report of the light armor materials program, California, USA, 1972. https://www.osti.gov/servlets/purl/4591356. 